Article

\title{
First-Line Pembrolizumab Mono- or Combination Therapy of Non-Small Cell Lung Cancer: Baseline Metabolic Biomarkers Predict Outcomes
}

\author{
David Lang ${ }^{1}{ }^{\oplus}$, Linda Ritzberger ${ }^{2}$, Vanessa Rambousek ${ }^{1}$, Andreas Horner ${ }^{1}$, Romana Wass ${ }^{1}$, Kaveh Akbari ${ }^{3}{ }^{(1)}$, \\ Bernhard Kaiser ${ }^{1}$, Jürgen Kronbichler ${ }^{4}$, Bernd Lamprecht ${ }^{1}$ and Michael Gabriel ${ }^{4, *}$
}

Citation: Lang, D.; Ritzberger, L.; Rambousek, V.; Horner, A.; Wass, R.; Akbari, K.; Kaiser, B.; Kronbichler, J.; Lamprecht, B.; Gabriel, M. First-Line Pembrolizumab Mono- or Combination Therapy of Non-Small Cell Lung Cancer: Baseline Metabolic Biomarkers Predict Outcomes. Cancers 2021, 13, 6096. https:// doi.org/10.3390/cancers13236096

Academic Editors: Sudip Mukherjee and Manash Paul

Received: 10 November 2021 Accepted: 1 December 2021 Published: 3 December 2021

Publisher's Note: MDPI stays neutral with regard to jurisdictional claims in published maps and institutional affiliations.

Copyright: (c) 2021 by the authors. Licensee MDPI, Basel, Switzerland. This article is an open access article distributed under the terms and conditions of the Creative Commons Attribution (CC BY) license (https:// creativecommons.org/licenses/by/ $4.0 /)$.
1 Department of Pulmonology, Johannes Kepler University Hospital Linz, Krankenhausstraße 9, 4020 Linz, Austria; david.lang@kepleruniklinikum.at (D.L.);

vanessa.rambousek@kepleruniklinikum.at (V.R.); andreas.horner@kepleruniklinikum.at (A.H.); romana.wass@kepleruniklinikum.at (R.W.); bernhardkaiser@gmx.at (B.K.); bernd.lamprecht@kepleruniklinikum.at (B.L.)

2 Medical Faculty, Johannes Kepler University Linz, Altenberger Strasse 69, 4020 Linz, Austria; linda.ritzberger@gmx.at

3 Central Radiology Institute, Johannes Kepler University Hospital Linz, Krankenhausstraße 9, 4020 Linz, Austria; kaveh.akbari@kepleruniklinikum.at

4 Institute of Nuclear Medicine and Endocrinology, Johannes Kepler University Hospital Linz, Krankenhausstraße 9, 4020 Linz, Austria; juergen.kronbichler@kepleruniklinikum.at

* Correspondence: michael.gabriel@kepleruniklinikum.at; Tel.: +43-5-7680-83-6166; Fax: +43-5-7680-83-6165

Simple Summary: Positron-emission tomography/computed tomography (PET/CT) is used for staging of non-small cell lung cancer (NSCLC) and can help to estimate prognosis in patients treated with immune checkpoint inhibitor (ICI) therapy. Most available data in that field were derived from cohorts treated in higher therapy lines using ICI monotherapy with different drugs. Currently, however, most advanced NSCLC patients receive first-line ICI treatment, often in combination with cytotoxic chemotherapy. We evaluated prognostic PET/CT biomarkers in 85 patients receiving first-line ICI, $70(82 \%)$ of them as a chemotherapy-ICI combination. We found that patients with a higher metabolically active tumor volume (MTV) had a significantly poorer survival and lower radiological response rate. In patients with high MTV, a concomitantly low bone marrow to liver ratio indicated a better prognosis. Our results demonstrate that PET/CT-derived biomarkers can aid therapeutic decision-making in ICI-treated NSCLC.

Abstract: Quantitative biomarkers derived from positron-emission tomography/computed tomography (PET/CT) have been suggested as prognostic variables in immune-checkpoint inhibitor (ICI) treated non-small cell lung cancer (NSCLC). As such, data for first-line ICI therapy and especially for chemotherapy-ICI combinations are still scarce, we retrospectively evaluated baseline ${ }^{18}$ F-FDGPET/CT of 85 consecutive patients receiving first-line pembrolizumab with chemotherapy $(n=70)$ or as monotherapy $(n=15)$. Maximum and mean standardized uptake value, total metabolic tumor volume (MTV), total lesion glycolysis, bone marrow-/and spleen to liver ratio (BLR/SLR) were calculated. Kaplan-Meier analyses and Cox regression models were used to assess progressionfree/overall survival (PFS/OS) and their determinant variables. Median follow-up was 12 months (M; 95\% confidence interval 10-14). Multivariate selection for PFS/OS revealed MTV as most relevant PET/CT biomarker $(p<0.001)$. Median PFS/OS were significantly longer in patients with $\mathrm{MTV} \leq 70 \mathrm{~mL}$ vs. $>70 \mathrm{~mL}$ (PFS: $10 \mathrm{M}$ (4-16) vs. $4 \mathrm{M}$ (3-5), $p=0.001$; OS: not reached vs. $10 \mathrm{M}$ (5-15), $p=0.004)$. Disease control rate was $81 \%$ vs. $53 \%$ for $\mathrm{MTV} \leq />70 \mathrm{~mL}(p=0.007)$. BLR $\leq 1.06 \mathrm{vs}$. $>1.06$ was associated with better outcomes (PFS: $8 \mathrm{M}(4-13)$ vs. $4 \mathrm{M}(3-6), p=0.034$; OS: $19 \mathrm{M}(12-/)$ vs. $6 \mathrm{M}(4-12), p=0.005)$. In patients with MTV $>70 \mathrm{~mL}$, concomitant BLR $\leq 1.06$ indicated a better prognosis. Higher MTV is associated with inferior PFS/OS in first-line ICI-treated NSCLC, with BLR allowing additional risk stratification. 
Keywords: total metabolic tumor volume; bone marrow to liver ratio; PET/CT; overall survival; immunotherapy; immune checkpoint inhibitor; standardized uptake value; response prediction

\section{Introduction}

Positron-emission tomography/computed tomography (PET/CT) is widely applied for staging both limited and advanced non-small cell lung cancer (NSCLC) [1-4]. In the last decade, immune-checkpoint inhibitors (ICI) directed against programmed cell death protein 1/programmed death-ligand 1 (PD-1/PD-L1) brought major therapeutic advances in NSCLC. Originally introduced as second-line therapy [5-8], PD-1/PD-L1blockade alone, or as a combination together with platinum-based doublet chemotherapy has moved into first-line treatment, leading to improved survival and frequently to longterm responses [2,9-13]. The challenge of predicting favorable responses is still ongoing, whereas biomarkers such as PD-L1 expression, tumor mutational burden, or presence of targetable genetic tumor alterations are being widely applied [14]. Moreover, clinical or laboratory parameters such as Eastern Cooperative Oncology Group (ECOG) performance status, neutrophil to lymphocyte ratio, lactate dehydrogenase, or C-reactive protein (CRP) have been suggested [14-16], but each of them provides only limited prognostic properties on the individual patient's level. Several biomarkers derived from PET/CT imaging have been reported to predict outcomes in various malignancies treated with ICI $[4,17,18]$. Concerning NSCLC treated with chemotherapy or ICI, especially volume-based PET/CT variables such as total (whole-body) metabolic tumor volume (MTV) and total lesion glycolysis (TLG) have been shown prognostic properties in terms of therapy response and survival [19-27]. Inflammatory processes within the tumor microenvironment are a major pathogenetic element in lung cancer [28], and biomarkers reflecting systemic inflammation are associated with reduced prognosis in lung cancer patients [14,16,29]. Of interest, the combination of the quantitative PET/CT biomarker MTV and the bloodbased inflammation biomarker derived neutrophil to lymphocyte ratio (DNLR) had a prognostic impact in NSCLC patients receiving ICI [27,30-32]. Importantly, ${ }^{18}$ F-FDG not only accumulates in tumor cells but also in activated immune cells both in malignant as well as in inflammatory processes [17,33-35]. In cancer patients, FDG uptake represents not only immunological processes in the tumor microenvironment, but also allows an estimation of the activity of lymphatic tissues, as usually expressed by the bone marrow to liver ratio (BLR) or the spleen to liver ratio (SLR) [35,36]. In malignant melanoma, higher BLR as well as SLR have been reported to be associated with an unfavorable prognosis [37,38]. High bone marrow activity has also been suggested as a prognostic biomarker in gynecological cancers $[39,40]$, and similar prognostic implications for high SLR could be shown for resected rectal or breast cancer [41,42]. Concerning NSCLC, bone marrow hypermetabolism has been reported as a prognostic factor after resection or in chemo(-radio)therapy settings [43-46]. Recently, high SLR has been reported as a significant predictor of reduced one-year PFS and two-year OS in first-line ICI monotherapy-treated advanced NSCLC patients [46].

Importantly, with some exceptions $[22,25,26,46]$, most of the existing evidence for quantitative PET/CT biomarkers in the context of ICI therapy is based on mono-immunotherapy cohorts in higher therapy lines, reflecting the initial regulatory approvals for nivolumab, pembrolizumab, and atezolizumab [5-8]. However, first-line ICI therapy in combination with chemotherapy or as monotherapy for tumors with PD-L1 expression $\geq 50 \%$ is currently regarded as standard of care $[1,2,10,11,47,48]$, Whether the existing data on quantitative PET/CT biomarkers can be transferred to the present therapeutic setting is thus questionable, especially due to the increased application of chemotherapy together with ICI.

Consequently, it was our aim to evaluate the clinical implications of quantitative biomarkers derived from pre-therapy ${ }^{18} \mathrm{~F}-\mathrm{FDG}-\mathrm{PET} / \mathrm{CT}$ in a well-characterized retrospec- 
tive cohort of patients receiving first-line ICI therapy with pembrolizumab in combination with chemotherapy or as monotherapy.

\section{Materials and Methods}

\subsection{Patients}

Eighty-five consecutive patients who had undergone ${ }^{18} \mathrm{~F}$-FDG-PET/CT before receiving first-line ICI therapy with pembrolizumab between June 2018 and December 2019 were retrospectively identified, follow-up was accomplished until December 2020. The patient cohort was derived from the institutional NSCLC immunotherapy registry of Kepler University Hospital Linz. The patient registry as well as the present evaluation have been approved by the ethics committees of the federal state of Upper Austria (EK Nr. $1139 / 2019)$, the need for patients' written informed consent was waived. All investigators had full access to the dataset used for this analysis. This study was conducted according to the REporting of studies Conducted using Observational Routinely collected health Data (RECORD) statement [49].

According to institutional standards, patients with PD-L1 expression $<50 \%$ received a chemo-ICI combination with pembrolizumab and carboplatin/pemetrexed for nonsquamous and carboplatin/paclitaxel for squamous histology [10,11]. Chemotherapy was given for four cycles with no further maintenance therapy, pembrolizumab was continued until progression or toxicity. Patients with PD-L1 expression $\geq 50 \%$ could either receive pembrolizumab monotherapy or a combination with platinum-based doublet chemotherapy [48]. Patients were retrospectively followed from first-line ICI therapy initiation on to death or censored at the date of last verified contact. Disease progression and survival were retrospectively assessed by reviewing the relevant medical records, especially imaging studies and death certificates. First-line therapy was defined as the first systemic treatment in stage IV or not otherwise treatable stage III disease, whereas previous therapies in potentially curable stages were not considered. We excluded patients in clinical trials, on ICI/ICI combination therapies and patients, who had previously received ICI for NSCLC or other malignancies.

\subsection{Image Acquisition Protocol and Analysis}

$\mathrm{PET} / \mathrm{CT}$ imaging was accomplished in the staging process usually two to four weeks before therapy initiation, however, a time span of a maximum of three months was allowed for inclusion if no tumor-specific therapy had been applied in that time. PET/CT scans were performed using a dedicated Siemens Biograph 40 Truepoint PET/CT scanner (Siemens Medical Solutions, Illinois). Patients kept fasting for at least six hours and blood glucose levels were measured before the injection of ${ }^{18} \mathrm{~F}$-FDG imaging to ensure that values were below $150 \mathrm{mg} / \mathrm{dL} .{ }^{18} \mathrm{~F}-\mathrm{FDG}$ was administered at a dose of $3.7 \mathrm{MBq} / \mathrm{kg}$ through a peripheral vein $60 \mathrm{~min}$ prior to imaging. Sequential overlapping emission scans of the neck, chest, abdomen, and pelvis were acquired. PET imaging was performed in 3D mode at $3 \mathrm{~min}$ per bed position, using the same axial field as the CT scan. We performed image reconstruction using an ordered subset expectation maximization iterative reconstruction algorithm on a $168 \times 168$-pixel matrix (AW-OSEM, 2 iterations, 8 subsets), followed by post-reconstruction filtering using a Gaussian filter applied at $5.0 \mathrm{~mm}$ full width at half maximum. All patients had attenuation-corrected images without intravenous contrast agent application. All PET/CT studies were reviewed by two specialist nuclear medicine physicians, who were blinded to the clinical data. For further analysis of quantitative PET/CT biomarkers, imaging data were transferred to a Hermes Workstation (Hermes Medical Solutions, Stockholm, Sweden). Semiquantitative analysis of ${ }^{18}$ F-FDG tumor uptake was performed with the Affinity Viewer ${ }^{\circledR}$ software tool (Version 1.0, Hermes Medical Solutions, Stockholm, Sweden). In this research, all SUV values were based on body weight. To determine the lesion SUVmax, isocontour regions of interest were semi-automatically drawn over abnormal findings at $50 \%$ of the maximum pixel value within the respective lesion, SUVmean and MTV were calculated using an SUV threshold of $41 \%$ of SUVmax 
according to our institution standard for lung cancer evaluation. The volumes of all segmented individual lesions, including the primary tumor as well as all metastatic lesions, were summed to obtain the whole-body MTV for each patient [50]. TLG was calculated as the product of the MTV and the SUVmean within the MTV [51]. BLR and SLR were calculated as the ratio of bone marrow/spleen and liver SUVmax. Bone marrow SUVmax was measured in the vertebral bodies of L1-L5, whereas areas with vertebral fractures and tumors/metastases were omitted. Spleen and liver SUVmax were calculated in a spherical VOI of three $\mathrm{cm}$ in the respective organ in an area with physiological morphology in the CT images, excluding, e.g., metastases.

\subsection{Laboratory Analyses}

C-reactive protein (CRP) and LDH were assessed using a Cobas ${ }^{\circledR} 8000$ modular analyzer (Roche Diagnostics International AG, Rotkreuz, Switzerland), lymphocyte count was analyzed using a Sysmex ${ }^{\circledR} \mathrm{XN}-3000$ hematology analyzer (Sysmex Europe GmbH, Norderstedt, Germany). Expression of PD-L1 in tumor cells was determined using a 22C3 assay for Autostainer Link 48 by Dako (Agilent Technologies, Santa Clara, CA, USA), a negative PD-L1 status was defined as membranous staining on $<1 \%$ of viable tumor cells.

\subsection{Response Assessment}

Radiological response to ICI therapy was routinely assessed every six to nine weeks by a CT scan of the chest and the upper abdomen using iodinated contrast medium unless contraindicated. Re-staging could be preponed due to suspected disease progression and additional imaging modalities such as cerebral magnetic resonance tomography could be conducted according to the treating clinician's judgment. The response was graded according to the Response Evaluation Criteria in Solid Tumors (RECIST), version 1.1 [52]. Disease control rate (DCR) was defined as patients with complete/partial remission (CR/PR) or stable disease (SD) versus those with progressive disease (PD). Patients who died before the first scheduled CT re-staging $(n=11)$ were counted as PD.

\subsection{Statistics}

Statistical analyses were performed using R (R: A Language and Environment for Statistical Computing; Version 3.6.0). Progression-free and overall survival (PFS, OS) for all patients and in specified subgroups were evaluated using Kaplan-Meier analyses, results were expressed as the median in months (M) with $95 \%$ confidence interval (CI). The KaplanMeier curves were statistically compared using the log-rank test, whereas a $p$-value $<0.05$ was regarded statistically significant. Uni- and multivariate models for PFS and OS were accomplished using Cox regression analyses. For MTV and BLR, cut-off values for PFS and OS were calculated using graphical analysis in quartiles and maximally selected rank (MSR) statistics. Clinical variables included in the multivariate models were age $(</ \geq 70$ years), sex, smoking history $(</ \geq 5$ pack years), histological subtype (adeno-, squamous-cell carcinoma), ECOG $(0,1 / \geq 2)$, CRP $(</ \geq 0.5 \mathrm{mg} / \mathrm{dL}), \mathrm{LDH}(</ \geq 250 \mathrm{U} / \mathrm{L})$, lymphocyte count $(</ \geq 1 \mathrm{G} / \mathrm{L})$, and PD-L1 expression (positive/negative). Patients with any of the relevant variables missing were excluded from the multivariate regression models.

\section{Results}

Quantitative PET/CT biomarkers were available in all 85 patients, patient disposition and baseline characteristics are presented in Figure 1 and Table 1 . At the time of analysis, 68 subjects had shown tumor progression, while 53 had died, resulting in a PFS of $5 \mathrm{M}$ (4-8) and an OS of $14 \mathrm{M}$ (7-18). Median follow-up time from baseline PET/CT acquisition to the end of observation was $12 \mathrm{M}(10-14)$, and the median time from baseline PET/CT to ICI therapy initiation was 23 days (21-29). 


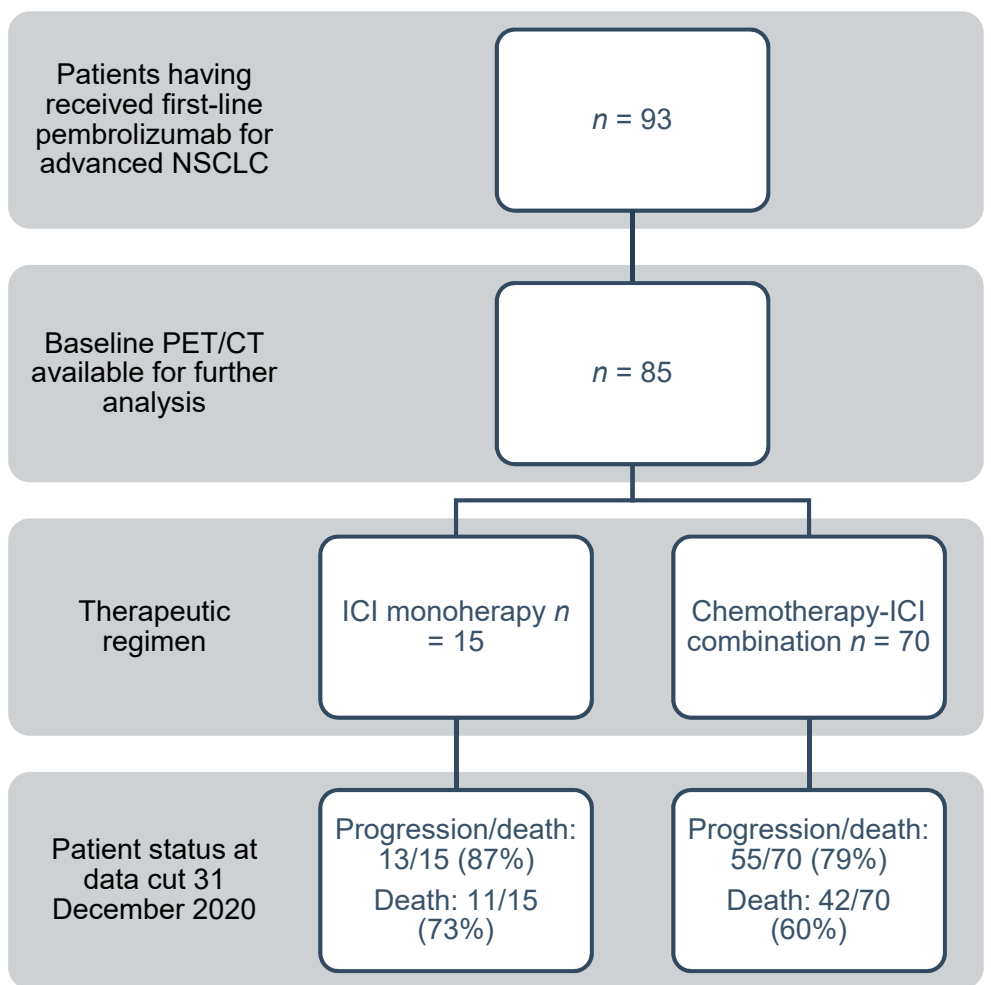

Figure 1. Patient disposition. NSCLC $=$ non-small cell lung cancer, PET/CT = positron-emission tomography/computed tomography, ICI = immune checkpoint inhibitor.

Table 1. Baseline characteristics. ECOG = Eastern Cooperative Oncology Group, SD = standard deviation, ICI = Immune checkpoint inhibitor, IQR = interquartile range, NSCLC = non-small cell lung cancer, $\mathrm{PD}-\mathrm{L} 1$ = programmed death-ligand 1, PET/CT = positron-emission tomography/computed tomography, SUV = standardized uptake value.

\begin{tabular}{cc}
\hline \multicolumn{2}{c}{ Patient Characteristics } \\
\hline Median age (range; years) & $64(38-81)$ \\
\hline Male sex $(n, \%)$ & $56(66)$ \\
\hline ECOG $(n, \%)$ & $42(49)$ \\
\hline 0 & $27(32)$ \\
\hline 1 & $16(19)$ \\
\hline $2+$ & $32(37.6)$ \\
\hline Presence of brain metastases $(n, \%)$ & $79(89.4)$ \\
\hline Smoking history $\geq 5$ pack years $(n, \%)$ & $44.5(24.3)$ \\
\hline Pack years (mean, SD) & $15(17.6)$ \\
\hline Therapy Characteristics & $3(2.5)$ \\
\hline ICI monotherapy $(n, \%)$ & $70(82.4)$ \\
\hline Median number of mono-ICI cycles (IQR) & $4(2)$ \\
\hline Chemotherapy-ICI combination $(n, \%)$ & $2.5(8)$ \\
\hline Median number of chemotherapy-ICI cycles (IQR) & \\
\hline Median number of mono-ICI maintenance cycles (IQR) & Tumor Characteristics \\
\hline
\end{tabular}


Table 1. Cont.

\begin{tabular}{|c|c|}
\hline \multicolumn{2}{|c|}{ Patient Characteristics } \\
\hline \multicolumn{2}{|l|}{ Histological subtype $(n, \%)$} \\
\hline Adenocarcinoma & $62(73)$ \\
\hline Squamous-cell carcinoma & $22(27)$ \\
\hline NSCLC not otherwise specified & $1(1)$ \\
\hline Positive PD-L1 status $(n, \%)$ & $49(58)$ \\
\hline \multicolumn{2}{|l|}{ PD-L1 expression $(n, \%)$} \\
\hline Not available & $5(6)$ \\
\hline$<1 \%$ & $31(36)$ \\
\hline $1-49 \%$ & $20(24)$ \\
\hline$\geq 50 \%$ & $29(34)$ \\
\hline \multicolumn{2}{|c|}{ Blood Biomarkers (mean, SD) } \\
\hline C-reactive protein $(\mathrm{mg} / \mathrm{dL})$ & $3.2(5.3)$ \\
\hline Lactate dehydrogenase (U/L) & $331.2(612)$ \\
\hline Lymphocyte count (G/L) & $1.3(0.78)$ \\
\hline \multicolumn{2}{|c|}{ PET/CT Biomarkers (mean, SD) } \\
\hline SUVmax & $16(6.7)$ \\
\hline SUVmean & $7(1.8)$ \\
\hline Total metabolic tumor volume $(\mathrm{mL})$ & $121.6(145.9)$ \\
\hline Total lesion glycolysis & $888.6(1184.3)$ \\
\hline Bone marrow to liver ratio & $1.04(0.27)$ \\
\hline Spleen to liver ratio & $0.81(0.12)$ \\
\hline
\end{tabular}

Using a Cox regression model including all quantitative PET/CT biomarkers, univariate analyses for PFS showed significance for MTV $(p<0.001)$, TLG $(p=0.002)$ and $\operatorname{BLR}(p=0.046)$, while stepwise multivariate selection revealed only MTV $(p<0.001)$ as significant. Similarly for OS, univariate analyses indicated significant interactions for $\operatorname{MTV}(p=0.001)$, TLG $(p=0.003)$ and BLR $(p=0.003)$, while multivariate selection again showed significance only for MTV $(p<0.001)$. Due to these results, MTV and BLR were defined as respective tumor- and immunologically related quantitative PET/CT biomarker for subsequent analyses. Using graphical analysis of quartiles and MSR calculation, the optimum cut-off values for MTV and BLR regarding PFS were determined at value of $70 \mathrm{~mL}$ and 1.06 , respectively.

PFS and OS differed significantly according to the defined MTV and BLR subgroups as shown in Table 2 and Figure 2, whereas lower MTV and lower BLR were associated with a more favorable prognosis.

The best radiological response according to RECIST for MTV and BLR subgroups is visualized in Table 3. Response rates differed significantly between patients with $\mathrm{MTV} \leq />70 \mathrm{~mL} ; \mathrm{DCR}$ was $81 \%$ for MTV $\leq 70 \mathrm{~mL}$ vs. $53 \%$ for MTV $>70 \mathrm{~mL}(p=0.007)$. 
Table 2. Median progression-free and overall survival according to MTV and BLR cutoff values. $\mathrm{CI}=$ confidence interval, $\mathrm{MTV}=$ metabolic tumor volume, $\mathrm{BLR}=$ bone marrow to liver ratio.

\begin{tabular}{|c|c|c|c|c|c|c|}
\hline & \multicolumn{3}{|c|}{ Progression-Free Survival } & \multicolumn{3}{|c|}{ Overall Survival } \\
\hline & Median & $95 \% \mathrm{CI}$ & $p$ & Median & $95 \% \mathrm{CI}$ & $p$ \\
\hline $\mathrm{MTV} \leq 70 \mathrm{~mL}$ & 10 & $4-16$ & \multirow{2}{*}{0.001} & $\begin{array}{c}\text { Not } \\
\text { reached }\end{array}$ & $7-/$ & \multirow{2}{*}{0.004} \\
\hline $\mathrm{MTV}>70 \mathrm{~mL}$ & 4 & $3-5$ & & 10 & $5-15$ & \\
\hline $\mathrm{BLR} \leq 1.06$ & 8 & $4-13$ & \multirow{2}{*}{0.034} & 19 & $12-/$ & \multirow{2}{*}{0.005} \\
\hline $\mathrm{BLR}>1.06$ & 4 & $3-6$ & & 6 & $4-12$ & \\
\hline
\end{tabular}

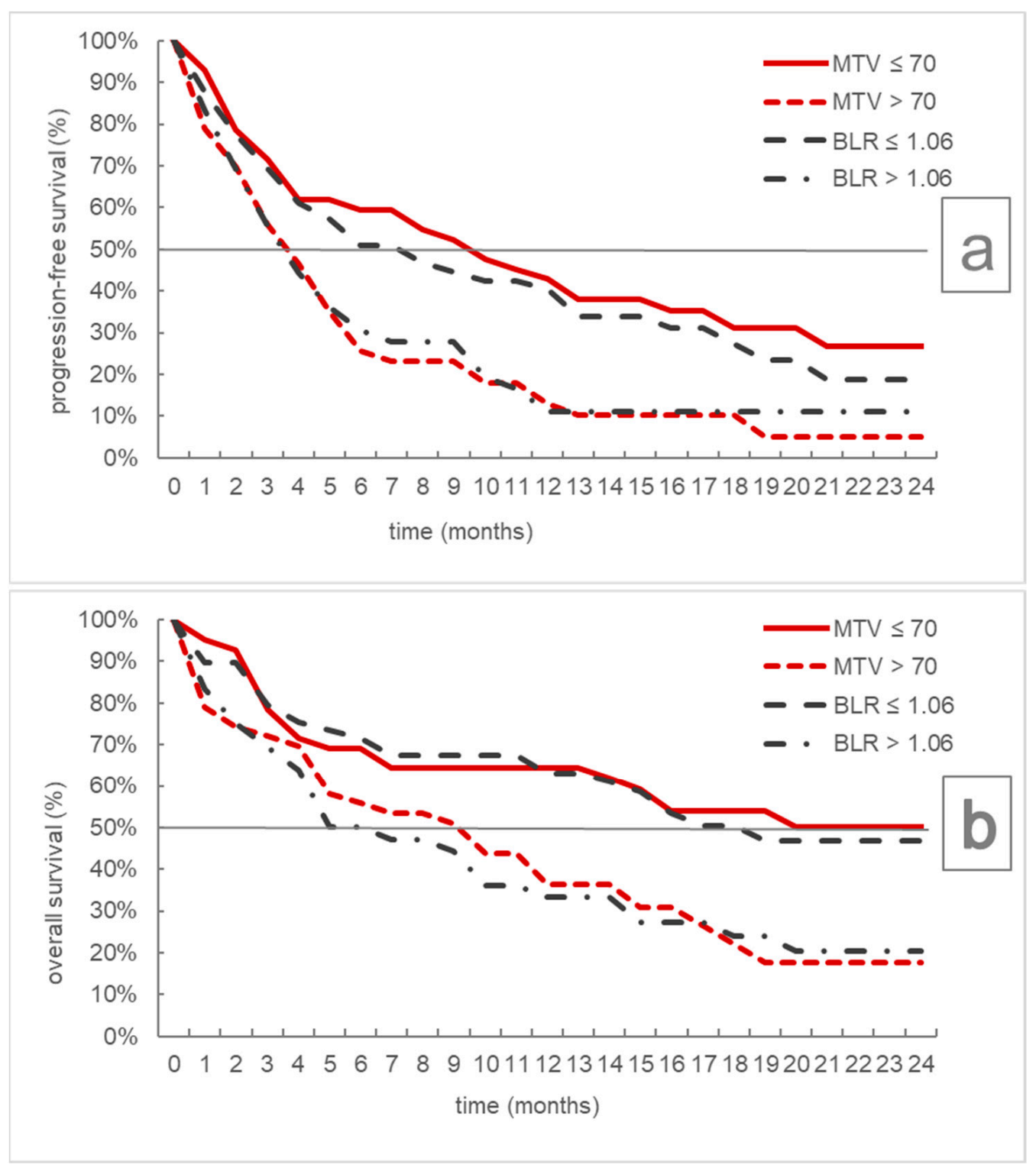

Figure 2. Kaplan-Meier curves for progression-free (a) and overall survival (b) according to MTV and BLR subgroups. MTV = metabolic tumor volume, BLR = bone marrow to liver ratio. 
Table 3. Radiological best response and disease control rate according to RECIST. RECIST = Response Evaluation Criteria in Solid Tumors, $\mathrm{CR}=$ complete remission, $\mathrm{PR}=$ partial remission, $\mathrm{SD}=$ stable disease, $\mathrm{PD}=$ progressive disease, $\mathrm{MTV}=$ metabolic tumor volume, BLR = bone marrow to liver ratio.

\begin{tabular}{|c|c|c|c|c|c|c|c|c|}
\hline & \multirow[b]{2}{*}{ Cut-Off } & \multirow[b]{2}{*}{$n$} & \multicolumn{4}{|c|}{ RECIST Best Response } & \multicolumn{2}{|c|}{ Disease Control Rate } \\
\hline & & & CR, PR & SD & PD & $p$ & CR, PR, SD & $p$ \\
\hline \multirow{2}{*}{ MTV } & $\leq 70 \mathrm{~mL}$ & 42 & $22(52)$ & $12(29)$ & $8(19)$ & \multirow{2}{*}{0.026} & $34(81)$ & \multirow{2}{*}{0.007} \\
\hline & $>70 \mathrm{~mL}$ & 43 & $14(33)$ & $9(21)$ & $20(46)$ & & $23(53)$ & \\
\hline \multirow{2}{*}{ BLR } & $\leq 1.06$ & 49 & $23(47)$ & $12(24)$ & $14(29)$ & \multirow{2}{*}{0.536} & $35(71)$ & \multirow{2}{*}{0.317} \\
\hline & $>1.06$ & 36 & $13(36)$ & $9(25)$ & $14(39)$ & & $22(61)$ & \\
\hline
\end{tabular}

In an exploratory approach, we estimated the prognostic power of MTV and BLR in the context of other, more established, patient- and tumor-related prognostic biomarkers in uni- and multivariate regression models for PFS and OS. As shown in Table 4, univariate analyses for PFS indicated a significant interaction for $\mathrm{LDH} \geq 250 \mathrm{U} / \mathrm{L}$, presence of brain metastases, and MTV $>70 \mathrm{~mL}$, while the multivariate model showed significance only for MTV. Concerning OS, univariate analyses revealed an ECOG performance status $\geq 2$, $\mathrm{LDH}>250 \mathrm{U} / \mathrm{L}, \mathrm{MTV}>70 \mathrm{~mL}$, and BLR $>1.06$ as significant, while ICI-monotherapy, $\mathrm{LDH} \geq 250 \mathrm{U} / \mathrm{L}, \mathrm{PD}-\mathrm{L} 1$ positivity, and BLR $>1.06$ had significant implications on the multivariate model.

Table 4. Uni- and multivariate analyses for progression-free and overall survival in all patients with full dataset available $(n=73)$. $p$-value indicates the statistical significance of the hazard ratio. $\mathrm{HR}=$ hazard ratio, $\mathrm{CI}=\mathrm{confidence}$ interval, ICI = immune checkpoint inhibitor, ECOG = Eastern Cooperative Oncology Group, SD = standard deviation, $\mathrm{IQR}=$ interquartile range, NSCLC = non-small cell lung cancer, $\mathrm{LDH}=$ lactate dehydrogenase, $\mathrm{CRP}=\mathrm{C}$-reactive protein, PD-L1 = programmed death-ligand 1, MTV = metabolic tumor volume, BLR = bone marrow to liver ratio.

\begin{tabular}{|c|c|c|c|c|c|c|c|c|}
\hline & \multicolumn{2}{|c|}{ Univariate } & \multicolumn{2}{|c|}{ Multivariate } & \multicolumn{2}{|c|}{ Univariate } & \multicolumn{2}{|c|}{ Multivariate } \\
\hline & $\begin{array}{c}\text { HR } \\
(95 \% \mathrm{CI})\end{array}$ & $p$ & $\begin{array}{c}\text { HR } \\
(95 \% \mathrm{CI}) \\
\end{array}$ & $p$ & HR $(95 \%$ CI $)$ & $p$ & $\begin{array}{c}\text { HR } \\
(95 \% \mathrm{CI})\end{array}$ & $p$ \\
\hline & \multicolumn{4}{|c|}{ Progression-Free Survival } & \multicolumn{4}{|c|}{ Overall Survival } \\
\hline $\begin{array}{l}\text { ICI-monotherapy vs. } \\
\text { chemotherapy-ICI } \\
\text { combination }\end{array}$ & $\begin{array}{c}1.33 \\
(0.70-0.52)\end{array}$ & 0.378 & & & $\begin{array}{c}1.50 \\
(0.74-3.04)\end{array}$ & 0.258 & $\begin{array}{c}4.01 \\
(1.63-9.87)\end{array}$ & 0.003 \\
\hline Sex (male vs. female) & $\begin{array}{c}1.13 \\
(0.66-1.95)\end{array}$ & 0.654 & & & $\begin{array}{c}1.01 \\
(0.55-1.84)\end{array}$ & 0.985 & & \\
\hline Age (>70 vs. $\leq 70$ years) & $\begin{array}{c}1.18 \\
(0.67-2.07)\end{array}$ & 0.567 & & & $\begin{array}{c}1.16 \\
(0.60-2.23)\end{array}$ & 0.666 & & \\
\hline ECOG $(2+$ vs. 0,1$)$ & $\begin{array}{c}1.64 \\
(0.88-3.03)\end{array}$ & 0.117 & & & $\begin{array}{c}2.20 \\
(1.11-4.38)\end{array}$ & 0.025 & & \\
\hline $\begin{array}{l}\text { Histology (squamous cell vs. } \\
\text { adenocarcinoma) }\end{array}$ & $\begin{array}{c}1.25 \\
(0.69-2.24)\end{array}$ & 0.464 & & & $\begin{array}{c}1.53 \\
(0.80-2.93)\end{array}$ & 0.199 & & \\
\hline$>5$ packyears (yes vs. no) & $\begin{array}{c}0.55 \\
(0.24-1.30)\end{array}$ & 0.174 & & & $\begin{array}{c}0.62 \\
(0.25-1.57)\end{array}$ & 0.315 & & \\
\hline LDH (>250 vs. $\leq 250$ U/L) & $\begin{array}{c}1.80 \\
(1.05-3.07)\end{array}$ & 0.032 & & & $\begin{array}{c}2.22 \\
(1.23-4.00)\end{array}$ & 0.008 & $\begin{array}{c}4.34 \\
(2.02-9.33)\end{array}$ & $<0.001$ \\
\hline CRP (>0.5 vs. $\leq 0.5 \mathrm{mg} / \mathrm{dL})$ & $\begin{array}{c}1.27 \\
(0.64-2.51)\end{array}$ & 0.492 & & & $\begin{array}{c}1.52 \\
(0.68-3.40)\end{array}$ & 0.306 & & \\
\hline PD-L1 (pos. vs. neg) & $\begin{array}{c}1.22 \\
(0.73-2.05)\end{array}$ & 0.457 & & & $\begin{array}{c}1.29 \\
(0.72-2.31)\end{array}$ & 0.384 & $\begin{array}{c}3.55 \\
(1.54-8.14)\end{array}$ & 0.026 \\
\hline $\begin{array}{l}\text { Lymphocyte count (>1 vs. } \leq 1 \\
\text { G/L) }\end{array}$ & $\begin{array}{c}1.16 \\
(0.68-1.98)\end{array}$ & 0.578 & & & $\begin{array}{c}1.03 \\
(0.57-1.87) \\
\end{array}$ & 0.914 & & \\
\hline $\begin{array}{c}\text { Presence of brain metastases } \\
\text { (yes vs. no) }\end{array}$ & $\begin{array}{c}1.70 \\
(1.02-2.84)\end{array}$ & 0.043 & & & $\begin{array}{c}1.45 \\
(0.85-2.59)\end{array}$ & 0.170 & & \\
\hline MTV (>70 vs. $\leq 70 \mathrm{~mL}$ ) & $\begin{array}{c}1.90 \\
(1.12-3.23)\end{array}$ & 0.017 & $\begin{array}{c}1.90 \\
(1.12-3.23)\end{array}$ & 0.015 & $\begin{array}{c}1.88 \\
(1.03-3.42)\end{array}$ & 0.040 & & \\
\hline BLR (>1.06 vs. $\leq 1.06)$ & $\begin{array}{c}1.63 \\
(0.98-2.72)\end{array}$ & 0.061 & & & $\begin{array}{c}2.10 \\
(1.18-3.74)\end{array}$ & 0.012 & $\begin{array}{c}2.09 \\
(1.16-3.75)\end{array}$ & 0.014 \\
\hline
\end{tabular}


To identify clinically relevant patient collectives defined by quantitative PET/CT biomarkers, four subgroups with MTV $\leq />70 \mathrm{~mL}$ and BLR $\leq />1.06$ were analyzed for PFS and OS, respectively. As shown in Table 5 and Figure 3, the subgroup with MTV $>70 \mathrm{~mL}$ and BLR $>1.06$ had considerably reduced PFS/OS, while patients with MTV $>70 \mathrm{~mL}$ showed a prognostic benefit if their BLR concomitantly was $\leq 1.06$. Two exemplary cases of patients with high/low MTV and BLR, respectively, are shown in Figure 4.

Table 5. Median progression-free and overall survival according to combined MTV and BLR subgroups values. CI = confidence interval, MTV = metabolic tumor volume, BLR = bone marrow to liver ratio.

\begin{tabular}{|c|c|c|c|c|c|c|c|}
\hline & & \multicolumn{3}{|c|}{ Progression-Free Survival } & \multicolumn{3}{|c|}{ Overall Survival } \\
\hline & $n$ & Median & $95 \% \mathrm{CI}$ & $p$ & Median & $95 \%$ CI & $p$ \\
\hline $\mathrm{MTV} \leq 70 \mathrm{~mL}+\mathrm{BLR} \leq 1.06$ & 31 & 9 & $4-18$ & \multirow{4}{*}{$<0.001$} & Not reached & $7-/$ & \multirow{4}{*}{$<0.001$} \\
\hline $\mathrm{MTV} \leq 70 \mathrm{~mL}+\mathrm{BLR}>1.06$ & 11 & 11 & $2-/-$ & & Not reached & $3-1$ & \\
\hline $\mathrm{MTV}>70 \mathrm{~mL}+\mathrm{BLR} \leq 1.06$ & 18 & 5.5 & $3-13$ & & 17 & $6-1$ & \\
\hline $\mathrm{MTV}>70 \mathrm{~mL}+\mathrm{BLR}>1.06$ & 25 & 3 & $2-5$ & & 5 & $2-10$ & \\
\hline
\end{tabular}

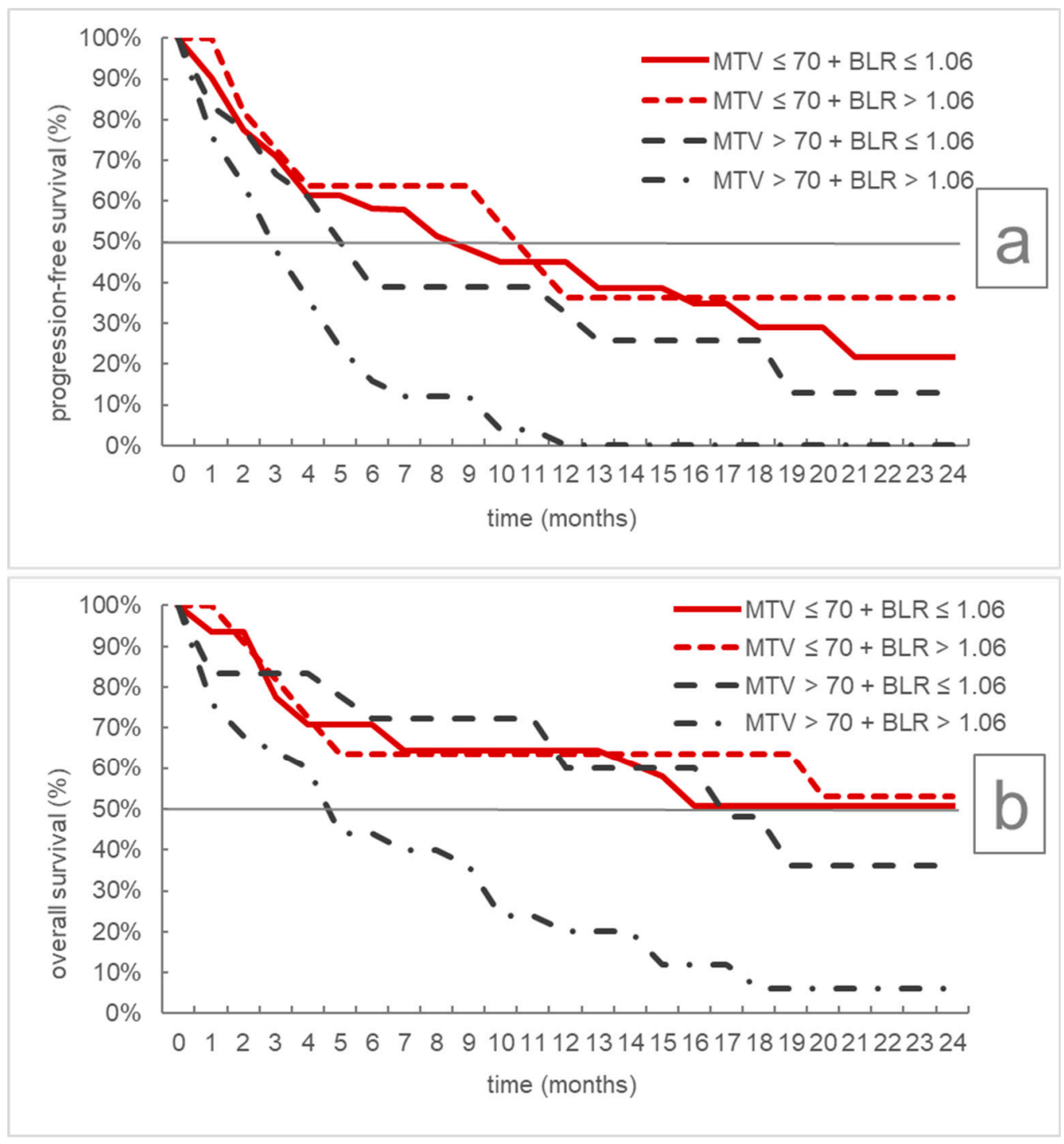

Figure 3. Kaplan-Meier curves for progression-free (a) and overall survival (b) according to combined MTV and BLR subgroups. MTV = metabolic tumor volume, $\mathrm{BLR}=$ bone marrow to liver ratio. 

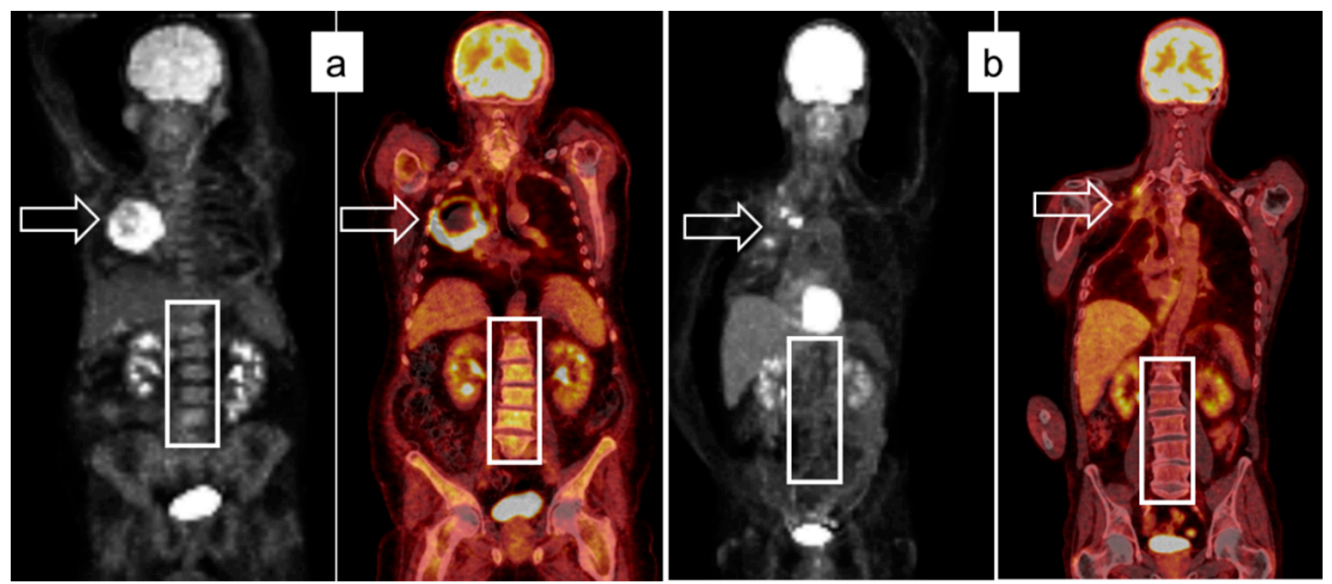

Figure 4. ${ }^{18}$ F-FDG-PET /CT studies of two cases demonstrating the relationship between MTV and BLR. The patient in (a) presented with a large, right upper lobe tumor with central necrosis (MTV $184 \mathrm{~mL}$ ) and had a high BLR of 1.73. The patient in (b) had a small intrapulmonary tumor recurrence and local bone metastases one year after initial chemotherapy, resection and radiotherapy of a stage III pancoast tumor of the right upper lobe. MTV was $8.1 \mathrm{~mL}$, BLR was 0.73. Boxes indicate the lumbar vertebral bodies; arrows indicate the localization of the primary tumor.

Figure $4{ }^{18}$ F-FDG-PET/CT studies of two cases demonstrating the relationship between MTV and BLR. The patient in (a) presented with a large, right upper lobe tumor with central necrosis (MTV $184 \mathrm{~mL}$ ) and had a high BLR of 1.73. The patient in (b) had a small intrapulmonary tumor recurrence and local bone metastases one year after initial chemotherapy, resection, and radiotherapy of a stage III Pancoast tumor of the right upper lobe. MTV was $8.1 \mathrm{~mL}$, BLR was 0.73 . Boxes indicate the lumbar vertebral bodies; arrows indicate the localization of the primary tumor.

In a subgroup analysis among patients with PD-L1 $\geq 50 \%(n=29)$, individuals having received ICI-monotherapy had inferior PFS and OS as compared to chemotherapy-ICI combination, regardless of MTV. For MTV $\leq 70 \mathrm{~mL}$, median PFS, and OS were not reached in the chemo-ICI group and amounted to $4 \mathrm{M}(1-6)$ and $14 \mathrm{M}(1-/)$ in the mono-ICI group, respectively. Patients with MTV $>70 \mathrm{~mL}$ had a median PFS and OS of $3 \mathrm{M}(2-10)$ and $6 \mathrm{M}$ (3-18) with chemo-ICI and $2.5 \mathrm{M} \mathrm{(1-7)} \mathrm{and} 3 \mathrm{M} \mathrm{(1-/)} \mathrm{with} \mathrm{mono-ICI.}$

\section{Discussion}

Our analyses indicate that among the quantitative PET/CT variables evaluated, MTV was the most relevant tumor-related prognostic biomarker in first-line ICI-treated NSCLC. Patients with lower MTV $\leq 70 \mathrm{~mL}$ had not only significantly longer PFS and OS, but also a significantly higher radiological response and disease control rate as compared to patients with a higher metabolic tumor burden. Additionally, bone marrow metabolism as assessed by BLR may have the potential to differentiate between favorable and adverse prognoses especially in those patients with higher MTV. In uni- and multivariate analyses for PFS and OS, both MTV and BLR showed hazard ratios comparable to traditional prognostic factors such as ECOG performance status or the presence of brain metastases.

From a clinical point of view, it is not surprising that metabolically active tumor burden as measured by MTV turned out as the most relevant tumor-related quantitative PET/CT biomarker in our cohort. Similar observations have been reported for various disease stages of NSCLC, using PET/CT or conventional CT imaging for both the determination of baseline tumor burden and response to ICI $[21,23,30,53,54]$. Concerning first-line treatment using mono-ICI therapy, Dall'Olio et al. recently reported an MTV $\geq 75 \mathrm{~cm}^{3}$ as a biomarker of poor prognosis in a cohort of 34 pembrolizumab-treated NSCLC patients with PDL1 expression $\geq 50 \%$, with an OS of $4.7 \mathrm{M}(0.3-9.1)$, while median OS was not reached in patients with MTV $<75 \mathrm{~m}^{3}$ [22]. These results are similar to our findings with an 
MTV threshold calculated at $70 \mathrm{~mL}$, but with a better OS of $10 \mathrm{M}$ (5-15) in our reported MTV $>70 \mathrm{~mL}$ group, which may be due to the addition of chemotherapy in the majority of patients. Seban et al. evaluated a cohort of 63 patients in the same therapeutic setting and identified MTV $>84 \mathrm{~cm}^{3}$ and SUVmean $>10.1$ as significant predictors of long-term benefit, PFS and OS [25]. Similarly, Yamaguchi et al. reported on 48 patients treated with first-line pembrolizumab for NSCLC with PD-L1 $\geq 50 \%$ and identified MTV as significant uni- and multivariate prognostic determinant [26]. In a cohort with 42 out of 57 NSCLC patients being treated with first-line ICI, Polverari et al. found associations of higher MTV and TLG with radiological disease progression [24]. All these studies consistently show very similar findings as reported in our cohort, especially concerning the major prognostic implications of MTV. However, in our patient collective, the vast majority received chemotherapy-ICI combination treatment, which reflects the current clinical practice in a considerably larger patient population as compared to the discussed evaluations of mono-ICI in NSCLC with PD-L1 $\geq 50 \%$. Our findings regarding BLR could have an additional impact on patient management, since lower BLR may identify patients with a better treatment response despite higher tumor burden. This resembles previous reports in cohorts of NSCLC and cutaneous melanoma patients, where the combination of MTV with DLNR [30,31], TLG with DLNR [27], as well as of MTV with BLR [37] provided similar prognostic information.

Reviewing these results, the question arises, how such biomarker information derived from PET/CT could benefit clinical decision making on the individual patient's level. Currently, for NSCLC patients with higher baseline MTV and BLR and without specific molecular targets, alternative first-line treatment options next to mono-ICI or chemotherapy-ICI combination are not available. Still, our findings have several implications on daily clinical practice: First, we suggest that PET/CT should be performed at baseline in all advanced NSCLC patients receiving ICI treatment. Given the current scarcity of prognostic biomarkers in these patients, our results and previous evaluations clearly suggest that biomarkers derived from PET/CT have prognostic relevance. Second, in line with other authors [22], we propose that patients with a high tumor burden as depicted by MTV should receive chemo-ICI combination rather than mono-ICI therapy. Third, patients at risk for early progression as identified by our reported PET/CT-derived biomarkers should be monitored more closely during initial therapy. Treating clinicians should timely ensure the availability of a complete panel of currently targetable genetic tumor alterations needed for second-line treatment decisions, such as the presence of a KRAS p.G12C mutation [55]. Such patients could also benefit from participation in clinical trials on substances aiming at enhancing the anti-cancer activity of existing (chemo-)immunotherapy agents, e.g., Canakinumab or Tiragolumab [56,57]. Moreover, novel molecular imaging tracers and "theranostic" substances currently under development for different tumor entities could provide new incentives in that field [4,58-62].

Our reported analysis has inherent limitations, but also strengths that should be addressed: The limited sample size, the single-center- and retrospective study design warrant further larger-scale and prospective trials in that field. Still, it represents a considerable portion of especially chemotherapy-ICI combination-treated NSCLC patients. This allows an insight into a patient collective of currently high clinical relevance, as most metastatic NSCLC patients receive such combination treatment at the moment. Another limitation is the current lack of standardized methods for the evaluation of quantitative PET/CT biomarkers, which limits the comparability between studies, although we sought to use similar approaches as suggested by previously published evaluations. In the future, methodological inconsistencies between centers, e.g., in the calculation of MTV, could be overcome by increased application of machine learning- and artificial intelligence-based segmentation and biomarker calculation algorithms, as well as by the rapidly evolving field of radiomics [24,63-65]. General limitations of PET/CT in thoracic malignancies naturally also apply to our reported findings: These include its limited sensitivity in small lesions or tumors with low cell density and reduced FDG avidity such as in bronchoalveolar carcinoma and misinterpretation of uptake in benign lesions caused by inflammatory 
processes [17]. In addition, we used standard RECIST rather than immunotherapy-specific iRECIST for radiological response assessment [66], and follow-up PET/CT was not conducted. Bone marrow hypermetabolism has been repeatedly reported as a prognostic factor in various tumor entities including NSCLC [37-40,43-45]; however, occasionally it can be difficult to differentiate between immunologically related lymphoid tissue hyperactivity and tumor- or trauma-associated bone abnormalities. Although we sought to exclude metastatic lesions of fractures within the region of interest in the lumbar vertebral bodies, diffuse metastatic bone marrow infiltration ultimately cannot be ruled out, as bone marrow biopsies are usually not assessed in stage IV NSCLC patients due to the lack of clinical consequences.

\section{Conclusions}

Quantitative baseline PET/CT biomarkers in ICI-treated advanced NSCLC patients can provide essential prognostic biomarker information, both concerning metabolic tumor characteristics, but also reflecting the immune system. The combination of high MTV and BLR identifies a clinically highly relevant group of patients with a poor prognosis that warrants intensified diagnostic and therapeutic efforts by the clinician as well as future research activity concerning additional treatment options.

Author Contributions: Conceptualization, D.L., L.R., V.R., A.H., K.A., B.K., B.L. and M.G.; Data curation, D.L., L.R., A.H., R.W., K.A., B.K., J.K. and M.G.; Formal analysis, D.L., V.R., A.H., R.W., K.A., B.K. and M.G.; Investigation, D.L., L.R., V.R., A.H., R.W., K.A., B.K., J.K. and M.G.; Methodology, D.L., L.R., V.R., A.H., R.W., K.A., B.K., B.L. and M.G.; Project administration, D.L., L.R., B.L. and M.G.; Resources, D.L., L.R., K.A., B.K., J.K., B.L. and M.G.; Software, L.R., K.A., B.K., J.K. and M.G.; Supervision, B.L. and M.G.; Validation, V.R., A.H., R.W., B.K., J.K. and M.G.; Visualization, D.L., K.A., B.K., J.K. and M.G.; Writing—original draft, D.L., L.R., V.R., A.H., B.K. and M.G.; Writing-review \& editing, D.L., L.R., V.R., A.H., R.W., K.A., B.K., J.K., B.L. and M.G. All authors have read and agreed to the published version of the manuscript.

Funding: This research received no external funding.

Institutional Review Board Statement: The patient registry as well as the present evaluation have been approved by the ethics committees of the federal state of Upper-Austria (EK Nr. 1139/2019).

Informed Consent Statement: The need for patients' written informed consent was waived according to the institutional ethics committee's regulations for non-interventional retrospective studies.

Data Availability Statement: As mandated by the Ethics Committee of Upper Austria, publication or dissemination of any possibly identifiable patient data from the present registry is prohibited. The dataset used for the present analyses contains very detailed and thus possibly identifiable patient data, therefore, publication of the full database is not possible. However, upon reasonable request to the authors and if permitted by the Ethics Committee of Upper Austria in an amendment to the study protocol, anonymized data can under certain circumstances be shared.

Acknowledgments: Supported by Johannes Kepler Open Access Publishing Fund.

Conflicts of Interest: The authors report no conflict of interest.

\section{References}

1. National Comprehensive Cancer Network Non-Small Cell Lung Cancer (Version 5.2021). Available online: https:/ /www.nccn. org/guidelines/guidelines-detail?category $=1 \& i d=1450$ (accessed on 3 July 2021).

2. $\quad$ Planchard, D.; Popat, S.; Kerr, K.; Novello, S.; Smit, E.F.; Faivre-Finn, C.; Mok, T.S.; Reck, M.; Van Schil, P.E.; Hellmann, M.D.; et al. Metastatic non-small cell lung cancer: ESMO Clinical Practice Guidelines for diagnosis, treatment and follow-up. Ann. Oncol. 2018, 29, iv192-iv237. [CrossRef]

3. Postmus, P.E.; Kerr, K.M.; Oudkerk, M.; Senan, S.; Waller, D.A.; Vansteenkiste, J.; Escriu, C.; Peters, S. Early and locally advanced non-small-cell lung cancer (NSCLC): ESMO Clinical Practice Guidelines for diagnosis, treatment and follow-up. Ann. Oncol. 2017, 28, iv1-iv21. [CrossRef]

4. Eze, C.; Schmidt-Hegemann, N.-S.; Sawicki, L.M.; Kirchner, J.; Roengvoraphoj, O.; Käsmann, L.; Mittlmeier, L.M.; Kunz, W.G.; Tufman, A.; Dinkel, J.; et al. PET/CT imaging for evaluation of multimodal treatment efficacy and toxicity in advanced NSCLC—Current state and future directions. Eur. J. Nucl. Med. Mol. Imaging 2021, 48, 3975-3989. [CrossRef] 
5. $\quad$ Borghaei, H.; Paz-Ares, L.; Horn, L.; Spigel, D.R.; Steins, M.; Ready, N.E.; Chow, L.Q.; Vokes, E.E.; Felip, E.; Holgado, E.; et al. Nivolumab versus Docetaxel in Advanced Nonsquamous Non-Small-Cell Lung Cancer. N. Engl. J. Med. 2015, 373, 1627-1639. [CrossRef] [PubMed]

6. $\quad$ Brahmer, J.; Reckamp, K.L.; Baas, P.; Crinò, L.; Eberhardt, W.E.E.; Poddubskaya, E.; Antonia, S.; Pluzanski, A.; Vokes, E.E.; Holgado, E.; et al. Nivolumab versus Docetaxel in Advanced Squamous-Cell Non-Small-Cell Lung Cancer. N. Engl. J. Med. 2015, 373, 123-135. [CrossRef]

7. Herbst, R.S.; Baas, P.; Kim, D.-W.; Felip, E.; Pérez-Gracia, J.L.; Han, J.-Y.; Molina, J.; Kim, J.-H.; Arvis, C.D.; Ahn, M.-J.; et al. Pembrolizumab versus docetaxel for previously treated, PD-L1-positive, advanced non-small-cell lung cancer (KEYNOTE-010): A randomised controlled trial. Lancet 2016, 387, 1540-1550. [CrossRef]

8. Rittmeyer, A.; Barlesi, F.; Waterkamp, D.; Park, K.; Ciardiello, F.; von Pawel, J.; Gadgeel, S.M.; Hida, T.; Kowalski, D.M.; Dols, M.C.; et al. Atezolizumab versus docetaxel in patients with previously treated non-small-cell lung cancer (OAK): A phase 3, open-label, multicentre randomised controlled trial. Lancet 2017, 389, 255-265. [CrossRef]

9. Ferrara, R.; Imbimbo, M.; Malouf, R.; Paget-Bailly, S.; Calais, F.; Marchal, C.; Westeel, V. Single or combined immune checkpoint inhibitors compared to first-line platinum-based chemotherapy with or without bevacizumab for people with advanced non-small cell lung cancer. Cochrane Database Syst. Rev. 2021, 4, 1465-1858. [CrossRef]

10. Paz-Ares, L.; Luft, A.; Vicente, D.; Tafreshi, A.; Gümüş, M.; Mazières, J.; Hermes, B.; Çay Şenler, F.; Csőszi, T.; Fülöp, A.; et al. Pembrolizumab plus Chemotherapy for Squamous Non-Small-Cell Lung Cancer. N. Engl. J. Med. 2018, 379, 2040-2051. [CrossRef] [PubMed]

11. Gandhi, L.; Rodríguez-Abreu, D.; Gadgeel, S.; Esteban, E.; Felip, E.; De Angelis, F.; Domine, M.; Clingan, P.; Hochmair, M.J.; Powell, S.F.; et al. Pembrolizumab plus Chemotherapy in Metastatic Non-Small-Cell Lung Cancer. N. Engl. J. Med. 2018, 378, 2078-2092. [CrossRef] [PubMed]

12. Reck, M.; Rodríguez-Abreu, D.; Robinson, A.G.; Hui, R.; Csőszi, T.; Fülöp, A.; Gottfried, M.; Peled, N.; Tafreshi, A.; Cuffe, S.; et al. Five-Year Outcomes with Pembrolizumab Versus Chemotherapy for Metastatic Non-Small-Cell Lung Cancer with PD-L1 Tumor Proportion Score $\geq$ 50\%. J. Clin. Oncol. 2021, 39, 2339-2349. [CrossRef] [PubMed]

13. Gadgeel, S.; Rodríguez-Abreu, D.; Speranza, G.; Esteban, E.; Felip, E.; Dómine, M.; Hui, R.; Hochmair, M.J.; Clingan, P.; Powell, S.F.; et al. Updated Analysis from KEYNOTE-189: Pembrolizumab or Placebo Plus Pemetrexed and Platinum for Previously Untreated Metastatic Nonsquamous Non-Small-Cell Lung Cancer. J. Clin. Oncol. 2020, 38, 1505-1517. [CrossRef]

14. Bodor, J.N.; Boumber, Y.; Borghaei, H. Biomarkers for immune checkpoint inhibition in non-small cell lung cancer (NSCLC). Cancer 2020, 126, 260-270. [CrossRef]

15. Huemer, F.; Lang, D.; Westphal, T.; Gampenrieder, S.P.; Hutarew, G.; Weiss, L.; Hackl, H.; Lamprecht, B.; Rinnerthaler, G.; Greil, R. Baseline Absolute Lymphocyte Count and ECOG Performance Score Are Associated with Survival in Advanced Non-Small Cell Lung Cancer Undergoing PD-1/PD-L1 Blockade. J. Clin. Med. 2019, 8, 1014. [CrossRef]

16. Riedl, J.M.; Barth, D.A.; Brueckl, W.M.; Zeitler, G.; Foris, V.; Mollnar, S.; Stotz, M.; Rossmann, C.H.; Terbuch, A.; Balic, M.; et al. C-Reactive Protein (CRP) Levels in Immune Checkpoint Inhibitor Response and Progression in Advanced Non-Small Cell Lung Cancer: A Bi-Center Study. Cancers 2020, 12, 2319. [CrossRef]

17. Lang, D.; Wahl, G.; Poier, N.; Graf, S.; Kiesl, D.; Lamprecht, B.; Gabriel, M. Impact of PET/CT for Assessing Response to Immunotherapy-A Clinical Perspective. J. Clin. Med. 2020, 9, 3483. [CrossRef] [PubMed]

18. Aide, N.; De Pontdeville, M.; Lopci, E. Evaluating response to immunotherapy with 18F-FDG PET/CT: Where do we stand? Eur. J. Nucl. Med. Mol. Imaging 2020, 47, 1019-1021. [CrossRef] [PubMed]

19. Evangelista, L.; Cuppari, L.; Menis, J.; Bonanno, L.; Reccia, P.; Frega, S.; Pasello, G. 18F-FDG PET/CT in non-small-cell lung cancer patients. Nucl. Med. Commun. 2019, 40, 802-807. [CrossRef]

20. Sharma, A.; Mohan, A.; Bhalla, A.S.; Sharma, M.C.; Vishnubhatla, S.; Das, C.J.; Pandey, A.K.; Sekhar Bal, C.; Patel, C.D.; Sharma, P.; et al. Role of Various Metabolic Parameters Derived from Baseline 18F-FDG PET/CT as Prognostic Markers in Non-Small Cell Lung Cancer Patients Undergoing Platinum-Based Chemotherapy. Clin. Nucl. Med. 2018, 43, e8-e17. [CrossRef]

21. Hashimoto, K.; Kaira, K.; Yamaguchi, O.; Mouri, A.; Shiono, A.; Miura, Y.; Murayama, Y.; Kobayashi, K.; Kagamu, H.; Kuji, I. Potential of FDG-PET as Prognostic Significance after anti-PD-1 Antibody against Patients with Previously Treated Non-Small Cell Lung Cancer. J. Clin. Med. 2020, 9, 725. [CrossRef]

22. Dall'Olio, F.G.; Calabrò, D.; Conci, N.; Argalia, G.; Marchese, P.V.; Fabbri, F.; Fragomeno, B.; Ricci, D.; Fanti, S.; Ambrosini, V.; et al. Baseline total metabolic tumour volume on 2-deoxy-2-[18F]fluoro-d-glucose positron emission tomography-computed tomography as a promising biomarker in patients with advanced non-small cell lung cancer treated with first-line pembrolizumab. Eur. J. Cancer 2021, 150, 99-107. [CrossRef]

23. Monaco, L.; Gemelli, M.; Gotuzzo, I.; Bauckneht, M.; Crivellaro, C.; Genova, C.; Cortinovis, D.; Zullo, L.; Ammoni, L.C.; Bernasconi, D.P.; et al. Metabolic Parameters as Biomarkers of Response to Immunotherapy and Prognosis in Non-Small Cell Lung Cancer (NSCLC): A Real World Experience. Cancers 2021, 13, 1634. [CrossRef]

24. Polverari, G.; Ceci, F.; Bertaglia, V.; Reale, M.L.; Rampado, O.; Gallio, E.; Passera, R.; Liberini, V.; Scapoli, P.; Arena, V.; et al. 18F-FDG Pet Parameters and Radiomics Features Analysis in Advanced Nsclc Treated with Immunotherapy as Predictors of Therapy Response and Survival. Cancers 2020, 12, 1163. [CrossRef] 
25. Seban, R.-D.; Assie, J.-B.; Giroux-Leprieur, E.; Massiani, M.-A.; Soussan, M.; Bonardel, G.; Chouaid, C.; Playe, M.; Goldfarb, L.; Duchemann, B.; et al. FDG-PET biomarkers associated with long-term benefit from first-line immunotherapy in patients with advanced non-small cell lung cancer. Ann. Nucl. Med. 2020, 34, 968-974. [CrossRef]

26. Yamaguchi, O.; Kaira, K.; Hashimoto, K.; Mouri, A.; Shiono, A.; Miura, Y.; Murayama, Y.; Kobayashi, K.; Kagamu, H.; Kuji, I. Tumor metabolic volume by 18F-FDG-PET as a prognostic predictor of first-line pembrolizumab for NSCLC patients with PD-L1 $\geq 50 \%$. Sci. Rep. 2020, 10, 14990. [CrossRef] [PubMed]

27. Castello, A.; Toschi, L.; Rossi, S.; Mazziotti, E.; Lopci, E. The immune-metabolic-prognostic index and clinical outcomes in patients with non-small cell lung carcinoma under checkpoint inhibitors. J. Cancer Res. Clin. Oncol. 2020, 146, 1235-1243. [CrossRef] [PubMed]

28. Tan, Z.; Xue, H.; Sun, Y.; Zhang, C.; Song, Y.; Qi, Y. The Role of Tumor Inflammatory Microenvironment in Lung Cancer. Front. Pharmacol. 2021, 12, 1168. [CrossRef] [PubMed]

29. Zhang, Y.; Chen, B.; Wang, L.; Wang, R.; Yang, X. Systemic immune-inflammation index is a promising noninvasive marker to predict survival of lung cancer. Medicine 2019, 98, e13788. [CrossRef]

30. Seban, R.-D.; Mezquita, L.; Berenbaum, A.; Dercle, L.; Botticella, A.; Le Pechoux, C.; Caramella, C.; Deutsch, E.; Grimaldi, S.; Adam, J.; et al. Baseline metabolic tumor burden on FDG PET/CT scans predicts outcome in advanced NSCLC patients treated with immune checkpoint inhibitors. Eur. J. Nucl. Med. Mol. Imaging 2020, 47, 1147-1157. [CrossRef] [PubMed]

31. Castello, A.; Rossi, S.; Mazziotti, E.; Toschi, L.; Lopci, E. Hyperprogressive Disease in Patients with Non-Small Cell Lung Cancer Treated with Checkpoint Inhibitors: The Role of 18 F-FDG PET/CT. J. Nucl. Med. 2020, 61, 821-826. [CrossRef]

32. Seban, R.-D.; Assié, J.-B.; Giroux-Leprieur, E.; Massiani, M.-A.; Soussan, M.; Bonardel, G.; Chouaid, C.; Playe, M.; Goldfarb, L.; Duchemann, B.; et al. Association of the Metabolic Score Using Baseline FDG-PET/CT and dNLR with Immunotherapy Outcomes in Advanced NSCLC Patients Treated with First-Line Pembrolizumab. Cancers 2020, 12, 2234. [CrossRef] [PubMed]

33. Fu, Y. Facilitative glucose transporter gene expression in human lymphocytes, monocytes, and macrophages: A role for GLUT isoforms 1, 3, and 5 in the immune response and foam cell formation. Blood Cells Mol. Dis. 2004, 32, 182-190. [CrossRef] [PubMed]

34. Giraudo, C.; Evangelista, L.; Fraia, A.S.; Lupi, A.; Quaia, E.; Cecchin, D.; Casali, M. Molecular Imaging of Pulmonary Inflammation and Infection. Int. J. Mol. Sci. 2020, 21, 894. [CrossRef] [PubMed]

35. Iravani, A.; Hicks, R.J. Imaging the Cancer Immune Environment and Its Response to Pharmacologic Intervention, Part 1: The Role of 18 F-FDG PET/CT. J. Nucl. Med. 2020, 61, 943-950. [CrossRef] [PubMed]

36. Schwenck, J.; Schörg, B.; Fiz, F.; Sonanini, D.; Forschner, A.; Eigentler, T.; Weide, B.; Martella, M.; Gonzalez-Menendez, I.; Campi, C.; et al. Cancer immunotherapy is accompanied by distinct metabolic patterns in primary and secondary lymphoid organs observed by non-invasive in vivo 18 F-FDG-PET. Theranostics 2020, 10, 925-937. [CrossRef]

37. Seban, R.-D.; Moya-Plana, A.; Antonios, L.; Yeh, R.; Marabelle, A.; Deutsch, E.; Schwartz, L.H.; Gómez, R.G.H.; Saenger, Y.; Robert, C.; et al. Prognostic 18F-FDG PET biomarkers in metastatic mucosal and cutaneous melanoma treated with immune checkpoint inhibitors targeting PD-1 and CTLA-4. Eur. J. Nucl. Med. Mol. Imaging 2020, 47, 2301-2312. [CrossRef]

38. Wong, A.; Callahan, J.; Keyaerts, M.; Neyns, B.; Mangana, J.; Aberle, S.; Herschtal, A.; Fullerton, S.; Milne, D.; Iravani, A.; et al. 18F-FDG PET/CT based spleen to liver ratio associates with clinical outcome to ipilimumab in patients with metastatic melanoma. Cancer Imaging 2020, 20, 36. [CrossRef]

39. Seban, R.-D.; Robert, C.; Dercle, L.; Yeh, R.; Dunant, A.; Reuze, S.; Schernberg, A.; Sun, R.; Mignot, F.; Terroir, M.; et al. Increased bone marrow SUVmax on 18F-FDG PET is associated with higher pelvic treatment failure in patients with cervical cancer treated by chemoradiotherapy and brachytherapy. Oncoimmunology 2019, 8, e1574197. [CrossRef]

40. Shimura, K.; Mabuchi, S.; Komura, N.; Yokoi, E.; Kozasa, K.; Sasano, T.; Kawano, M.; Matsumoto, Y.; Watabe, T.; Kodama, M.; et al. Prognostic significance of bone marrow FDG uptake in patients with gynecological cancer. Sci. Rep. 2021, 11, 2257. [CrossRef]

41. Kim, S.Y.; Moon, C.M.; Yoon, H.-J.; Kim, B.S.; Lim, J.Y.; Kim, T.O.; Choe, A.R.; Tae, C.H.; Kim, S.-E.; Jung, H.-K.; et al. Diffuse splenic FDG uptake is predictive of clinical outcomes in patients with rectal cancer. Sci. Rep. 2019, 9, 1313. [CrossRef] [PubMed]

42. Seban, R.-D.; Rouzier, R.; Latouche, A.; Deleval, N.; Guinebretiere, J.-M.; Buvat, I.; Bidard, F.-C.; Champion, L. Total metabolic tumor volume and spleen metabolism on baseline [18F]-FDG PET/CT as independent prognostic biomarkers of recurrence in resected breast cancer. Eur. J. Nucl. Med. Mol. Imaging 2021, 48, 3560-3570. [CrossRef]

43. Lee, J.W.; Na, J.O.; Kang, D.-Y.; Lee, S.Y.; Lee, S.M. Prognostic Significance of FDG Uptake of Bone Marrow on PET/CT in Patients with Non-Small-Cell Lung Cancer After Curative Surgical Resection. Clin. Lung Cancer 2017, 18, 198-206. [CrossRef] [PubMed]

44. Lee, J.W.; Seo, K.H.; Kim, E.-S.; Lee, S.M. The role of 18F-fluorodeoxyglucose uptake of bone marrow on PET/CT in predicting clinical outcomes in non-small cell lung cancer patients treated with chemoradiotherapy. Eur. Radiol. 2017, 27, 1912-1921. [CrossRef] [PubMed]

45. Prévost, S.; Boucher, L.; Larivée, P.; Boileau, R.; Bénard, F. Bone marrow hypermetabolism on 18F-FDG PET as a survival prognostic factor in non-small cell lung cancer. J. Nucl. Med. 2006, 47, 559-565.

46. Seban, R.-D.; Assié, J.-B.; Giroux-Leprieur, E.; Massiani, M.-A.; Bonardel, G.; Chouaid, C.; Deleval, N.; Richard, C.; Mezquita, L.; Girard, N.; et al. Prognostic value of inflammatory response biomarkers using peripheral blood and [18F]-FDG PET/CT in advanced NSCLC patients treated with first-line chemo- or immunotherapy. Lung Cancer 2021, 159, 45-55. [CrossRef]

47. Socinski, M.A.; Jotte, R.M.; Cappuzzo, F.; Orlandi, F.; Stroyakovskiy, D.; Nogami, N.; Rodríguez-Abreu, D.; Moro-Sibilot, D.; Thomas, C.A.; Barlesi, F.; et al. Atezolizumab for First-Line Treatment of Metastatic Nonsquamous NSCLC. N. Engl. J. Med. 2018, 378, 2288-2301. [CrossRef] 
48. Reck, M.; Rodríguez-Abreu, D.; Robinson, A.G.; Hui, R.; Csőszi, T.; Fülöp, A.; Gottfried, M.; Peled, N.; Tafreshi, A.; Cuffe, S.; et al. Pembrolizumab versus Chemotherapy for PD-L1-Positive Non-Small-Cell Lung Cancer. N. Engl. J. Med. 2016, 375, $1823-1833$. [CrossRef]

49. Benchimol, E.I.; Smeeth, L.; Guttmann, A.; Harron, K.; Moher, D.; Petersen, I.; Sørensen, H.T.; von Elm, E.; Langan, S.M. The REporting of studies Conducted using Observational Routinely-collected health Data (RECORD) Statement. PLoS Med. 2015, 12, e1001885. [CrossRef]

50. Im, H.-J.; Bradshaw, T.; Solaiyappan, M.; Cho, S.Y. Current Methods to Define Metabolic Tumor Volume in Positron Emission Tomography: Which One is Better? Nucl. Med. Mol. Imaging 2018, 52, 5-15. [CrossRef] [PubMed]

51. Chen, H.H.W.; Chiu, N.-T.; Su, W.-C.; Guo, H.-R.; Lee, B.-F. Prognostic Value of Whole-Body Total Lesion Glycolysis at Pretreatment FDG PET/CT in Non-Small Cell Lung Cancer. Radiology 2012, 264, 559-566. [CrossRef]

52. Eisenhauer, E.A.; Therasse, P.; Bogaerts, J.; Schwartz, L.H.; Sargent, D.; Ford, R.; Dancey, J.; Arbuck, S.; Gwyther, S.; Mooney, M.; et al. New response evaluation criteria in solid tumours: Revised RECIST guideline (version 1.1). Eur. J. Cancer 2009, 45, $228-247$. [CrossRef] [PubMed]

53. Su, X.-D.; Xie, H.-J.; Liu, Q.-W.; Mo, Y.-X.; Long, H.; Rong, T.-H. The prognostic impact of tumor volume on stage I non-small cell lung cancer. Lung Cancer 2017, 104, 91-97. [CrossRef]

54. van Laar, M.; van Amsterdam, W.A.C.; van Lindert, A.S.R.; de Jong, P.A.; Verhoeff, J.J.C. Prognostic factors for overall survival of stage III non-small cell lung cancer patients on computed tomography: A systematic review and meta-analysis. Radiother. Oncol. 2020, 151, 152-175. [CrossRef]

55. Skoulidis, F.; Li, B.T.; Dy, G.K.; Price, T.J.; Falchook, G.S.; Wolf, J.; Italiano, A.; Schuler, M.; Borghaei, H.; Barlesi, F.; et al. Sotorasib for Lung Cancers with KRAS p.G12C Mutation. N. Engl. J. Med. 2021, 384, 2371-2381. [CrossRef]

56. Patil, N.; Cho, B.C.; Johnson, M.; Caro, R.B.; Spira, A.; Chiu, C.; Molden, N.; Pham, T.; Yang, X.; Choi, Y.; et al. P77.02 Efficacy of Tiragolumab + Atezolizumab in PD-L1 IHC and TIGIT Subgroups in the Phase II CITYSCAPE Study in First-Line NSCLC. J. Thorac. Oncol. 2021, 16, S635-S636. [CrossRef]

57. Paz-Ares, L.G.; Garon, E.B.; Ardizzoni, A.; Barlesi, F.; Cho, B.C.; Castro, G.; De Marchi, P.; Felip, E.; Goto, Y.; Greystoke, A.; et al. The CANOPY program: Canakinumab in patients (pts) with non-small cell lung cancer (NSCLC). J. Clin. Oncol. 2019, 37, TPS9124. [CrossRef]

58. Decazes, P.; Bohn, P. Immunotherapy by Immune Checkpoint Inhibitors and Nuclear Medicine Imaging: Current and Future Applications. Cancers 2020, 12, 371. [CrossRef]

59. Bensch, F.; van der Veen, E.L.; Lub-de Hooge, M.N.; Jorritsma-Smit, A.; Boellaard, R.; Kok, I.C.; Oosting, S.F.; Schröder, C.P.; Hiltermann, T.J.N.; van der Wekken, A.J.; et al. 89Zr-atezolizumab imaging as a non-invasive approach to assess clinical response to PD-L1 blockade in cancer. Nat. Med. 2018, 24, 1852-1858. [CrossRef] [PubMed]

60. Seifert, R.; Kessel, K.; Schlack, K.; Weber, M.; Herrmann, K.; Spanke, M.; Fendler, W.P.; Hadaschik, B.; Kleesiek, J.; Schäfers, M.; et al. PSMA PET total tumor volume predicts outcome of patients with advanced prostate cancer receiving [177Lu]Lu-PSMA-617 radioligand therapy in a bicentric analysis. Eur. J. Nucl. Med. Mol. Imaging 2021, 48, 1200-1210. [CrossRef] [PubMed]

61. Kumar, D.; Lisok, A.; Dahmane, E.; McCoy, M.; Shelake, S.; Chatterjee, S.; Allaj, V.; Sysa-Shah, P.; Wharram, B.; Lesniak, W.G.; et al. Peptide-based PET quantifies target engagement of PD-L1 therapeutics. J. Clin. Investig. 2019, 129, 616-630. [CrossRef]

62. Ballal, S.; Yadav, M.P.; Kramer, V.; Moon, E.S.; Roesch, F.; Tripathi, M.; Mallick, S.; ArunRaj, S.T.; Bal, C. A theranostic approach of [68Ga]Ga-DOTA.SA.FAPi PET/CT-guided [177Lu]Lu-DOTA.SA.FAPi radionuclide therapy in an end-stage breast cancer patient: New frontier in targeted radionuclide therapy. Eur. J. Nucl. Med. Mol. Imaging 2021, 48, 942-944. [CrossRef]

63. Froelich, J.W.; Salavati, A. Artificial Intelligence in PET/CT Is about to Make Whole-Body Tumor Burden Measurements a Clinical Reality. Radiology 2020, 294, 453-454. [CrossRef] [PubMed]

64. Yang, F.; Simpson, G.; Young, L.; Ford, J.; Dogan, N.; Wang, L. Impact of contouring variability on oncological PET radiomics features in the lung. Sci. Rep. 2020, 10, 369. [CrossRef] [PubMed]

65. Dissaux, G.; Visvikis, D.; Da-ano, R.; Pradier, O.; Chajon, E.; Barillot, I.; Duvergé, L.; Masson, I.; Abgral, R.; Santiago Ribeiro, M.-J.; et al. Pretreatment 18 F-FDG PET/CT Radiomics Predict Local Recurrence in Patients Treated with Stereotactic Body Radiotherapy for Early-Stage Non-Small Cell Lung Cancer: A Multicentric Study. J. Nucl. Med. 2020, 61, 814-820. [CrossRef] [PubMed]

66. Seymour, L.; Bogaerts, J.; Perrone, A.; Ford, R.; Schwartz, L.H.; Mandrekar, S.; Lin, N.U.; Litière, S.; Dancey, J.; Chen, A.; et al. iRECIST: Guidelines for response criteria for use in trials testing immunotherapeutics. Lancet Oncol. 2017, 18, e143-e152. [CrossRef] 